\title{
Fenômeno de Lúcio fatal: relato de caso de autópsia
}

\author{
Fatal Lucio's phenomenom: an autopsy case report
}

Fernando Peixoto Ferraz de Campos $^{a}$, Cristiane Rúbia Ferreirab ${ }^{b}$ Amaro Nunes Duarte Neto ${ }^{c}$

Campos FPF, Ferreira CR, Duarte Neto AN. Fenômeno de Lúcio fatal: relato de caso de autópsia. Autopsy Case Rep [Internet]. 2011;1(2):10-9.

\section{RESUMO}

A Hanseníase de Lúcio e Alvarado, considerada a forma mais anérgica do espectro imunológico hansênico, caracteriza-se por espessamento e infiltração difusa, com alopecia difusa e total, associado a comprometimento sistêmico importante.Nesse polo da doença, os bacilos são numerosos em todos os tecidos. A alta carga bacilar no endotélio e o desenvolvimento de vasculite leucocitoclástica de pequenos e médios vasos resultam em extensas áreas necrótico-ulcerativas, denominada fenômeno de Lúcio. Apresentamos a seguir um caso de autópsia de um paciente do sexo feminino que apresentava lesões cutâneas, há 20 anos, sem diagnóstico definido, com piora dos sintomas e aparecimento de novas lesões, há 3 semanas da internação. Devido à gravidade da doença e às conseqüentes complicações infecciosas, a paciente apresentou evolução fatal. A avaliação anátomo patológica mostrou comprometimento sistêmico por lepra e múltiplas úlceras cutâneas. As lesões cutâneas eram secundárias a vasculite leucocitoclástica e oclusão vascular, consistente com Reação de Lucio.

Unitermos: Fenômeno de Lucio; Hanseníase; Vasculite; Histopatologia; Necrose.

\section{ABSTRACT}

The diffuse leprosy of Lucio and Alvarado is considered the most anergic spectrum of leprosy and is characterized by a generalized skin infiltration, with a diffuse and total alopecia associated with a systemic involvement. When the number of bacilli in the endothelium is high a medium and small vessel's leukocytoclastic vasculitis develop over a diffuse and generalized cutaneous involvement by leprosy, what leads to large necrotic and ulcerative lesions, named after Lucio's phenomenon. We present an autopsy case of a female patient who has been presenting ulcerated lesions for the last 20 years without a specific diagnosis. Three weeks before the patient's admission the lesions got worse and new ones appeared. Due to the extension of cutaneous

\footnotetext{
a Divisão de Clínica Médica Hospital Universitário - Universidade de São Paulo, São Paulo/SP - Brasil.

b Serviço de Anatomia Patológica do Hospital Universitário - Universidade de São Paulo, São Paulo/SP - Brasil.

c Hospital das Clínicas da Faculdade de Medicina - Universidade de São Paulo, São Paulo/SP - Brasil.
} 
involvement and consequent infectious complications the patient evolved to a fatal outcome. The pathological evaluation revealed systemic involvement by leprosy and multiple skin ulceration. The cutaneous lesions were due to leukocitoclastic vasculitis and vascular occlusion, compatible with Lucio's phenomenon .

Keywords: Lucio'sphenomenum; Leprosy; Vasculitis; Histopathology; Necrosis.

\section{INTRODUÇÃO}

A Hanseníase é uma doença granulomatosa crônica, causada pelo Mycobacterium leprae, ainda endêmica em muitas regiões do mundo apesar da terapia eficaz com várias drogas, já disponíveis há 3 décadas. O Brasil é o segundo país do mundo em número de casos diagnosticados, seguido pela Indonésia, sendo a Índia o país de maior incidência. No ano de 2009 foram diagnosticados 37.610 casos no Brasil, o que representou $15,3 \%$ de todos os casos diagnosticados no mundo. Dentre todas as regiões do Brasil, a região norte é a que apresenta o maior número de casos e a região sul, o menor número. No estado de São Paulo foram diagnosticados 1843 casos novos no ano de 2009 e no município de São Paulo $246^{\mathrm{d}}$ casos no mesmo período. ${ }^{1,2}$ A Hanseníase se apresenta com amplo espectro de manifestações clínicas, variando desde formas paucibacilares, relacionada à efetiva resposta imune celular, até formas disseminadas, multibacilares, acompanhadas de resposta imune deficitária. ${ }^{3} \mathrm{O}$ polo multibacilar compreende as formas lepromatosa e a borderline, envolvendo pele, nervos e com manifestações sistêmicas extra-cutâneas em olhos, articulações, sistema retículo endotelial, com adenomegalia e hepatoesplenomegalia, entre outros. Episódios agudos de exacerbação dos sintomas são frequentemente o motivo da procura pelo atendimento médico. ${ }^{4}$ Estas reações são classificadas em tipo 1 e tipo 2. A reação do tipo1 é definida como reação imunecelular, caracterizada por aparecimento de novas lesões e exacerbação das lesões antigas com aumento da dor, eritema, edema e espessamento de nervos. A reação tipo 2 é mediada pela deposição de imunocomplexos com aparecimento de eritema nodoso, artralgia, dor, espessamento neural, iridociclite, e epididimite, dentre outros. ${ }^{5}$ Lesões necróticas podem se desenvolver em pacientes que apresentam a forma lepromatosa ou borderline como parte da reação do eritema nodoso lepromatoso (ENL), ou também como complicação rara, grave e difusa, conhecida como fenômeno de Lúcio ( $F L)$, também chamado de eritema necrotizante (EN), que pode ocorrer na forma pura, primitiva e difusa ou Lepra de Lucio e Latapí, originalmente descrita no México. ${ }^{6}$

Apresentamos a seguir o relato de caso fatal de uma paciente que apresentou reação necrotizante de Lúcio internada no Hospital Universitário da Universidade de São Paulo.

\section{Relato de Caso}

Paciente do sexo feminino, 67 anos de idade, branca, residente na cidade de São Paulo, portadora de diabetes mellitus tipo II em tratamento irregular. Há aproximadamente 20 anos apresenta aparecimento de úlceras em membros inferiores e região plantar. Há 20 dias novas úlceras apareceram nas nádegas, região sacral, membros superiores e face. Estas úlceras extensas iniciaram com secreção hialina seguida de secreção purulenta. Apresentava desde então edema generalizado. Há 15 dias queixou-se de tosse com expectoração amarelada seguida de dispnéia progressiva aos esforços. Não apresentava febre ou emagrecimento. Vinha fazendo uso de prednisona e anti-inflamatório não hormonal prescrito para tratamento de dor articular.

Ao exame físico da entrada apresentava-se consciente contactando, porém em mal estado geral, edemaciada, observando-se madarose bilateral e nariz em sela. Pressão arterial $120 \times 80 \mathrm{mmHg}$, pulso $100 \mathrm{bpm}$, freqüência respiratória de $24 \mathrm{rpm}$, temperatura $36^{\circ} \mathrm{C}$, glicemia capilar $99 \mathrm{mg} / \mathrm{dl}$. Estertores crepitantes em base do pulmão esquerdo acompanhada de propedêutica de derrame pleural ipsilateral. Presença de úlceras extensas e indolores, algumas isoladas, outras confluentes, algumas superficiais, outras profundas, com bordas irregulares e por vezes, deposição de material fibrinóide amarelado. Exposição de tendões e necrose do te-

d Dados fornecidos pela Unidade de Vigilância à Saúde - Butantã, da Secretaria de Higiene e Saúde da Prefeitura Municipal de São Paulo, SP. 
cido subcutâneo nas faces extensora e flexora dos membros inferiores, nádegas, membros superiores, dorso das mãos, face, na região malar e nariz, além de lesão eritemato-infiltrativa com necrose no pavilhão auricular esquerdo. Dedos das mãos em flexão (mão em garra) e perda dos $2^{\circ}, 3^{\circ}, 4^{\circ}$ e $5^{\circ}$ pododáctilos do pé direito (Figuras 1-3).

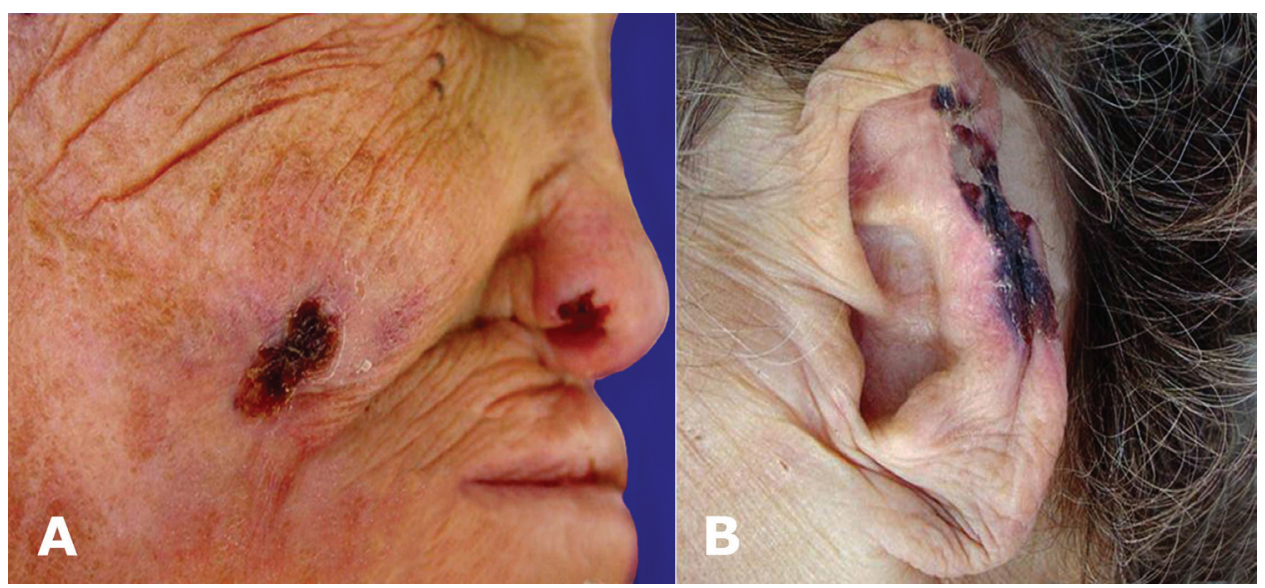

Figura 1 - A - Lesão necrótica na região malar direita e na asa do nariz recoberta de crosta hemática e necrose da epiderme. Deformidade em sela do nariz. B - Lesão necrótica do pavilhão auricular esquerdo.

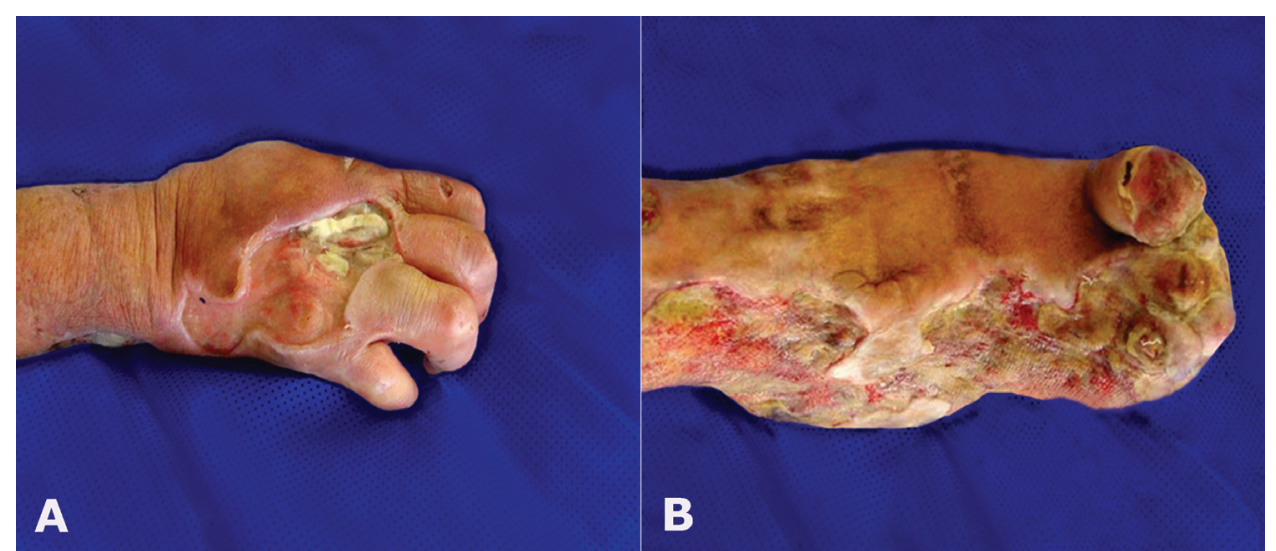

Figura 2 - A - Infiltração mixedematosa da mão direita sobre a qual há extensa úlcera de bordas elevados com fundo limpo, profunda com exposição de tendões. Deformidade da mão em garra. B - Pé direito com extensas úlceras necróticas recobertas por fibrina e material necrótico comprometendo até hipoderme com perda dos $2^{\circ}, 3^{\circ}, 4^{\circ}$ e $5^{\circ}$ pododáctilos. Nota-se na face medial do pé lesão cicatricial hiperpigmentada.

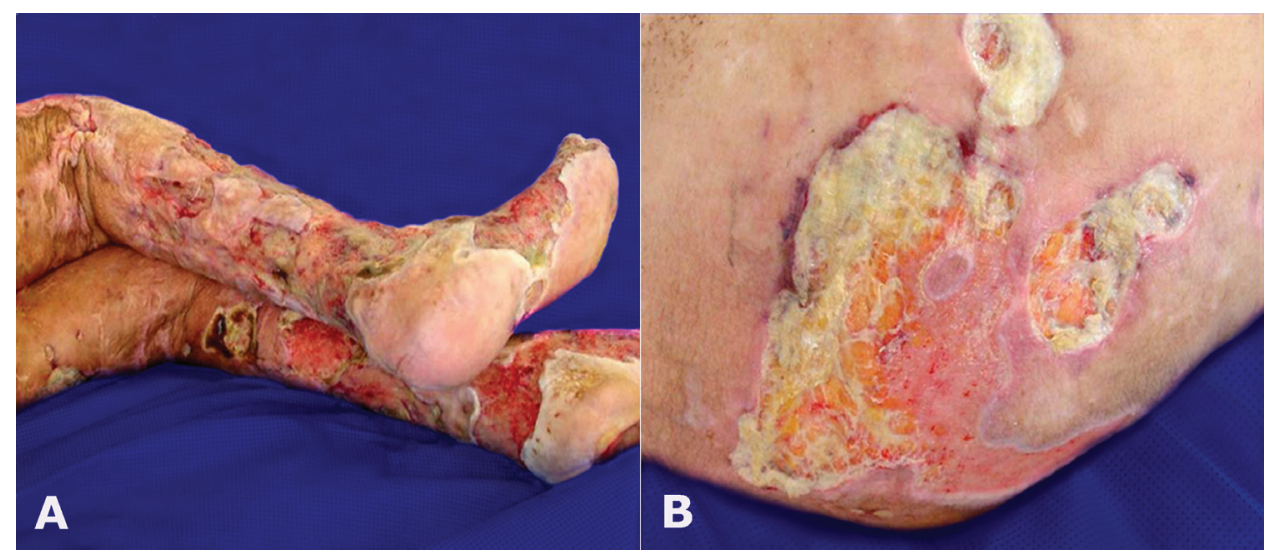

Figura 3 - A - Membros inferiores com extensas áreas ulceradas por necrose tecidual da epiderme e derme algumas com fundo limpo outras recobertas por fibrina e debris, entremeadas por tecido cicatricial com hiperpigmentação. B Áreas de necrose superficial e profunda atingindo a hipoderme em nádegas. 
A Tabela 1 mostra os exames laboratoriais de entrada.

Tabela 1 - Exames laboratoriais à admissão

\begin{tabular}{lccccc}
\hline Hemoglobina & $\mathrm{g} / \mathrm{dl}$ & 5,4 & T.Protrombina & $\mathrm{INR}$ & 1,76 \\
Hematócrito & $\%$ & 18 & $\mathrm{AST}$ & $\mathrm{U} / \mathrm{l}$ & 57 \\
VCM/RDW & $\mathrm{fl} \%$ & $65 / 24,4$ & $\mathrm{ALT}$ & $\mathrm{U} / \mathrm{l}$ & 24 \\
Leucócitos & $\mathrm{mm}$ & 11400 & Proteínas totais & $\mathrm{g} / \mathrm{dl}$ & 5,4 \\
bastonetes & $\%$ & 0 & Albumina & $\mathrm{g} / \mathrm{dl}$ & 1,8 \\
segmentados & $\%$ & 85 & Potássio & $\mathrm{mEq} / \mathrm{l}$ & 3,5 \\
eosinófilos & $\%$ & 0 & Sódio & $\mathrm{mEq} / \mathrm{l}$ & 144 \\
basófilos & $\%$ & 0 & Creatinina & $\mathrm{mg} / \mathrm{dl}$ & 0,4 \\
linfócitos & $\%$ & 12 & Uréia & $\mathrm{mg} / \mathrm{dl}$ & 26 \\
monócito & $\%$ & 3 & glicemia & $\mathrm{mg} / \mathrm{dl}$ & 99 \\
plaquetas & $\mathrm{mm}$ & 318000 & PCR & $\mathrm{ng} / \mathrm{ml}$ & 203 \\
\hline
\end{tabular}

T Protrombina $=$ Tempo de Protrombina .

Urina tipo $1 \mathrm{com}$ proteinúria, cilindrúria hialina, leucocitúria 108.000/mm3 e hematúria 20.000 mm3.

$\mathrm{RX}$ tórax mostrava derrame pleural à esquerda e foco bronco pneumônico em base esquerda. A punção do líquido pleural revelou resultados compatíveis com o diagnóstico de derrame pleural parapneumônico, com culturas negativas. Ecocardiograma com aumento do átrio esquerdo (42 mm), calcificação do anel mitral com insuficiência discreta da válvula mitral, função sistólica do VE preservada (FEVE 73\%), septo e parede posterior com 10 $\mathrm{mm}$ de espessura. USG de abdome sem alteração de vísceras abdominais.

Devido ao quadro cutâneo, iniciou-se investigação diagnóstica através do exame anátomo-patológico pele, assim como a paciente foi internada em UTI sendo tratada com esquema antibiótico com ceftriaxone, clindamicina, fluconazol, além de transfusão de concentrado de hemácias e tratamento de suporte respiratório e hemodinâmico. O estado clínico deteriorou, evoluindo com hipotensão, hipotermia e insuficiência renal aguda, seguida de parada cardiorrespiratória, após 9 dias de internação em unidade de terapia intensiva. O diagnóstico foi determinado pela autópsia.

\section{Autópsia}

$\mathrm{Na}$ inspeção externa observaram-se múltiplas lesões ulceradas cutâneas, que foram descritas acima. $\mathrm{Na}$ abertura das cavidades presença de órgãos tópicos, com grande quantidade de líquido ascítico de coloração amarelo-citrino e deposição de material fibrináceo amarelado em cápsula hepática e alças intestinais, indicando peritonite fibrinóide. O pâncreas (peso - 89,0 g, valor normal $(\mathrm{VN})=$ $60 \mathrm{~g}-135 \mathrm{~g}$ ) apresentava áreas necróticas, friáveis e amareladas características de esteato necrose.

Fígado apresentando parênquima de coloração castanho-vinhosa, sem lesões macroscópicas ou visceromegalia (peso $-1452,0 \mathrm{~g}, \mathrm{VN}=1100 \mathrm{~g}$ a $1450 \mathrm{~g}$ ). Baço aumentado de volume (peso - 404,0 $\mathrm{g}, \mathrm{VN}=112 \mathrm{~g}$ ) e com parênquima friável aos cortes, consistente com baço tipo reacional. $\mathrm{Na}$ abertura longitudinal do trato gastrointestinal, observaramse 2 lesões ulceradas na região do antro gástrico, medindo a maior cerca de $2,0 \mathrm{~cm}$ de diâmetro. Os rins apresentavam superfície externa granular com depressões, e aos cortes, parênquima com coloração rosa-pálido (rim direito - 178,0 g; rim esquerdo - 180,0 g, VN = para ambos $240 \mathrm{~g}$ a $350 \mathrm{~g}$ ). $\mathrm{Na}$ cavidade torácica, discreto derrame pleural de coloração amarelo-citrino, com pulmões de parênquima esponjoso com aspecto congesto (pulmão direito - 377,0 g, VN = 360 g a 570 g; pulmão esquerdo $-289,0 \mathrm{~g}, \mathrm{VN}=325 \mathrm{~g}$ a $480 \mathrm{~g}$ ). O coração (peso $-314,0 \mathrm{~g}, \mathrm{VN}=151 \mathrm{~g}$ a $324 \mathrm{~g}$ ) apresentava hipertrofia do ventrículo esquerdo e artérias coronárias indicando doença aterosclerótica cárdio-vascular. Presença ainda de aterosclerose da aorta torácica e abdominal.

Os recortes histológicos demonstraram nas bordas e fundo das lesões ulceradas cutâneas presença de vasos com permeação de neutrófilos e necrose fibrinóide da parede vascular, característico de vasculite leucocitoclástica (Figura 4). 


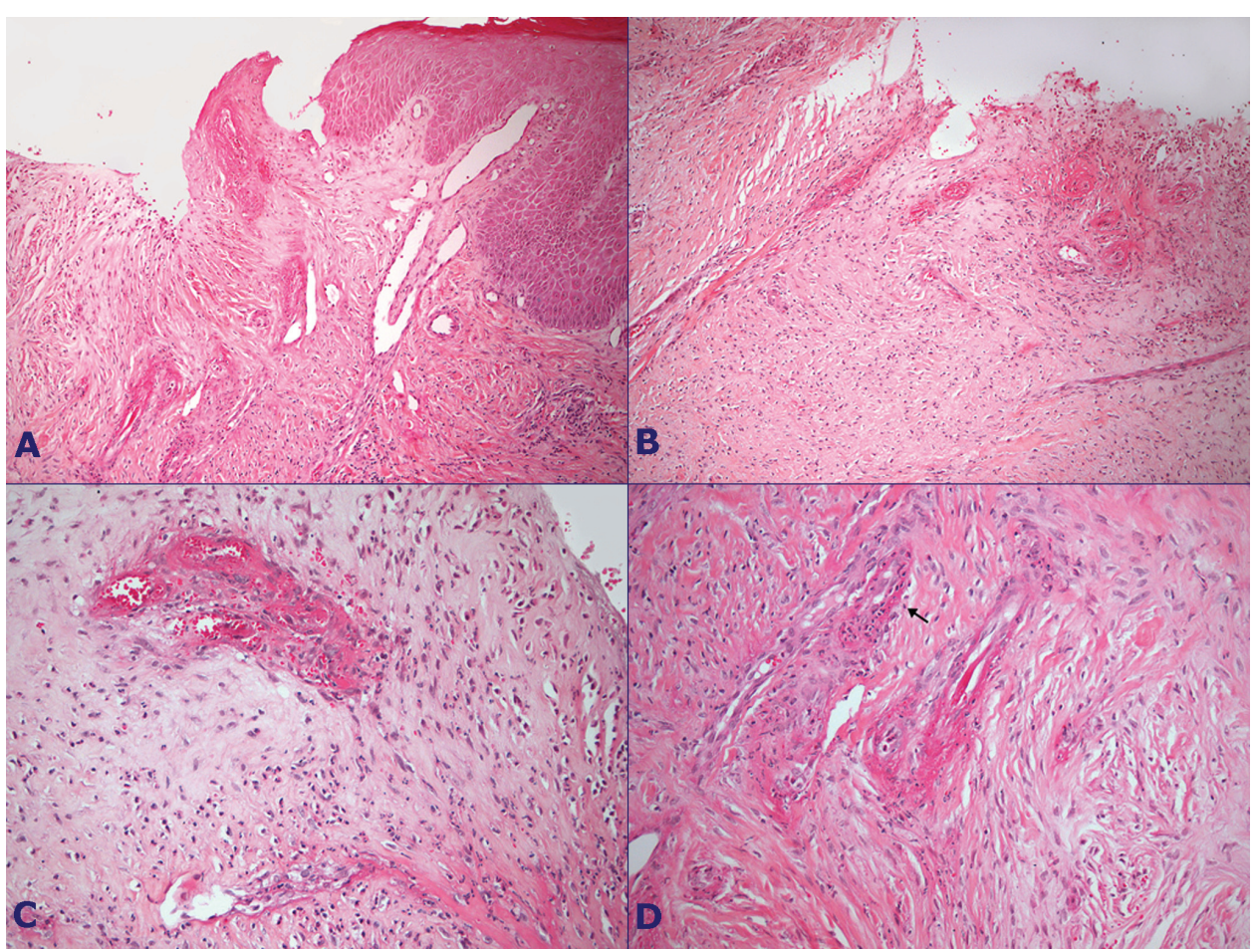

Figura 4 - Fotomicrografias mostrando: A e B - Borda e fundo de úlcera cutânea com discreto infiltrado inflamatório misto e vasos com vasculite leucocitoclástica (HE - 100X). C - Vaso com necrose fibrinóide da parede e trombo de fibrina luminal (HE - 200X). D - Vaso com vasculite leucocitoclástica (seta), com necrose fibrinóide e discreta permeação de neutrófilos na parede (HE - 200X).

Na derme reticular profunda presença de alguns vasos com espessamento miointimal da parede e outros com trombos de fibrina intra-luminal. $\mathrm{Na}$ pele das áreas adjacentes às lesões ulceradas, observou-se na derme infiltrado inflamatório crônico linfomononuclear rico em histiócitos com citoplasma xantomizado, além de alguns nervos espessados com neurite associada. A pesquisa de bacilos álcool acido resistentes (BAAR) foi positiva, com presença de numerosos bacilos em histiócitos xantomatosos (células de Virchow), em filetes neurais cutâneos, e em células endoteliais dos vasos cutâneos. O quadro histológico foi compatível com o diagnóstico de Hanseníase multibacilar difusa com fenômeno de Lúcio (Figuras 5 e 6).

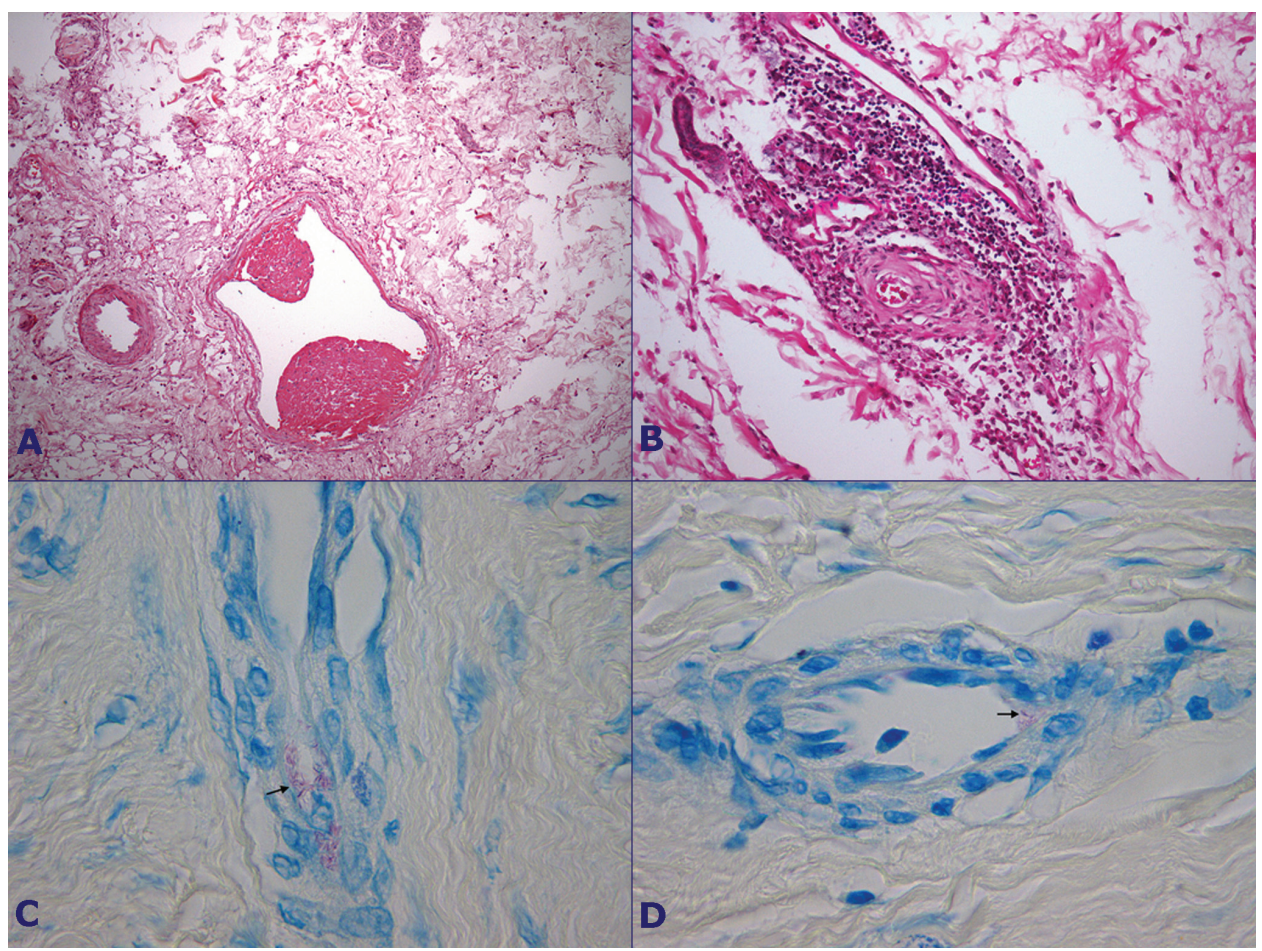

Figura 5 - Fotomicrografias mostrando: A - Vaso da derme reticular localizado na periferia de lesão ulcerada apresentando trombo fibrino-hemático luminal (HE - 100X). B - Vaso da derme reticular apresentando hiperplasia miointimal da parede com infiltrado inflamatório crônico linfo-histiocitário perifericamente (HE - 200X). C e D - Micobacterium leprae (seta) colonizando o endotélio de vasos cutâneos (Ziehl-Neelsen - 1000X). 
Associado às alterações cutâneas, observou-se acometimento sistêmico, com hanseníase visceral. No fígado, presença de múltiplos agregados microscópicos de histiócitos com citoplasma xantomizado (células de Virchow), também designado como leproma miliar, no parênquima lobular na zona 3, em topografia periférica à veia centrolobular e principalmente acometendo os espaços-porta, caracterizando hepatite lepromatosa. No baço também havia múltiplos agregados microscópicos de histiócitos com citoplasma xantomizado, localizados principalmente na polpa branca, além de congestão da polpa vermelha (Figura 7 ).

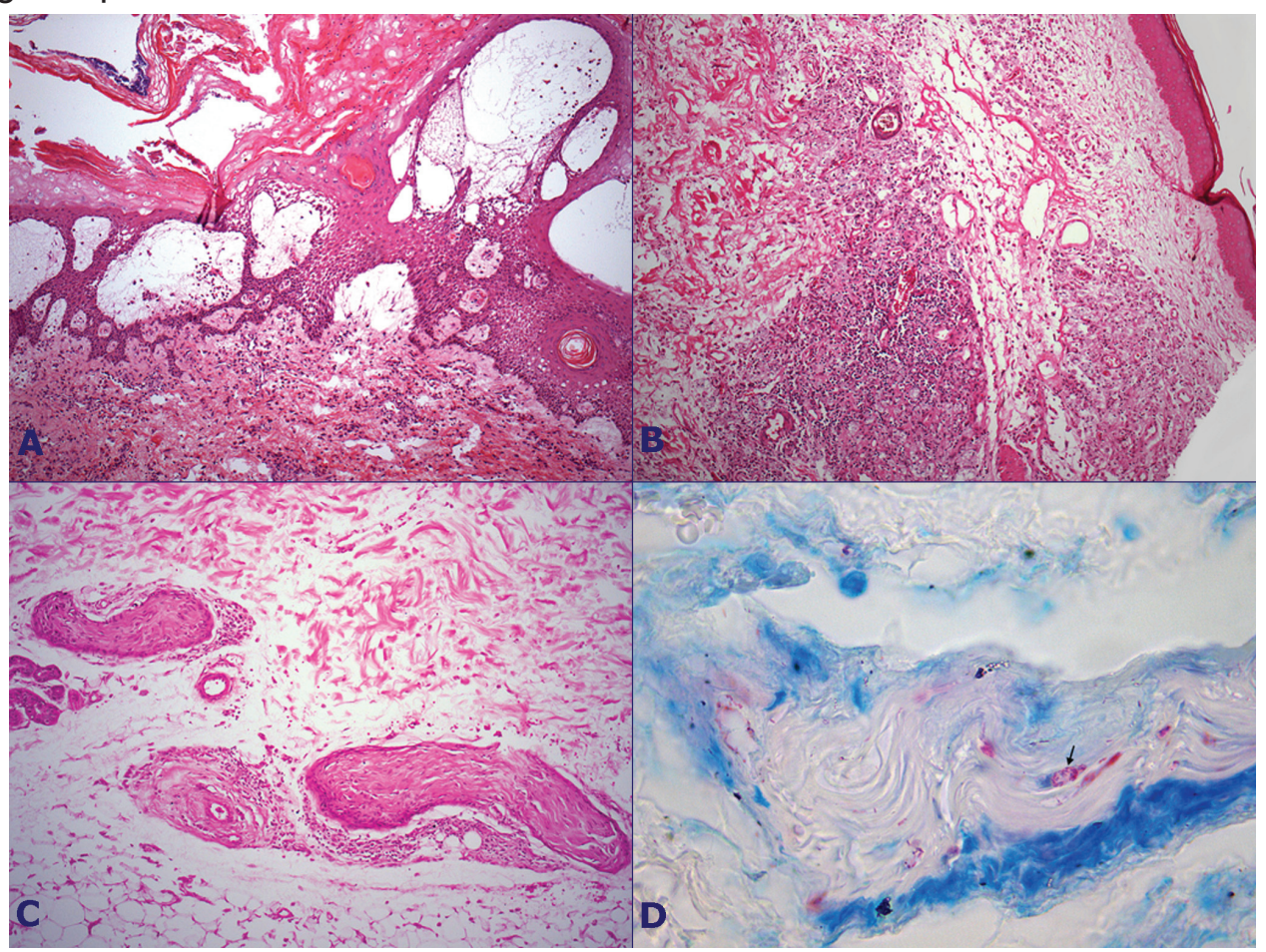

Figura 6 - Fotomicrografias mostrando: A e B - Pele com intensa espongiose e formação de vesículas intra-epidérmicas representando alterações isquêmicas iniciais (HE - 100X). B - Pele com infiltrado inflamatório crônico rico em histiócitos xantomizados (células de Virchow) localizada em área de aspecto macroscópico mixedematoso (HE - 100X). C - Filetes neurais dérmicos com espessamento e neurite associada (HE - 100X). D - Micobacterium leprae (seta) em filete neural dérmico (Ziehl-Neelsen - 1000X).

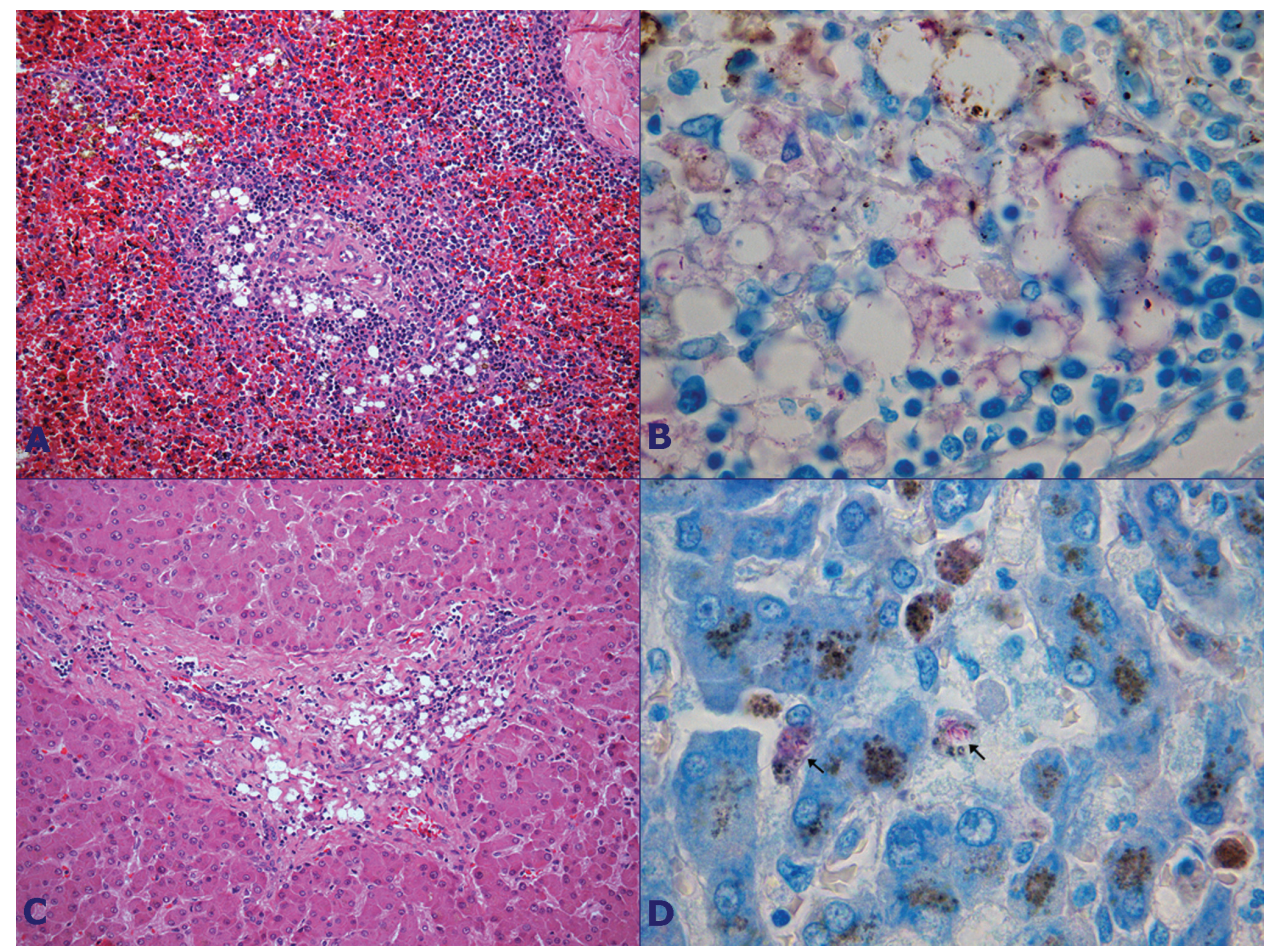

Figura 7 - Fotomicrografias mostrando: A e B - Baço apresentando agregado de histiócitos xantomizados (células de Virchow) na polpa branca, também designado como leproma miliar (HE - 200X). B - Agregado de histiócitos xantomizados no baço com numerosos bacilos $M$. leprae no citoplasma (Ziehl-Neelsen - 1000X). C - Leproma miliar em espaço-porta hepático (HE - 200X). D - Histiócitos com numerosos bacilos M. lepre no citoplasma (setas), localizado em sinusóide hepático (Ziehl-Neelsen - 1000X). 
O mesmo quadro histológico também foi observado focalmente na medula óssea e supra-renal, todos com pesquisa de BAAR positiva. Presença ainda de espessamento de nervo em base da língua.

Foram evidenciados ainda achados secundários à infecção bacteriana cutânea e sistêmica, compatíveis com quadro de septicemia, com pre- sença de pancreatite aguda com múltiplos focos de esteatonecrose, peritonite aguda fibrinosa e broncopneumonia (Figura 8).

Os rins apresentavam necrose tubular aguda, além de nefroesclerose benigna, característico do rim vascular, e alguns glomérulos com expansão mensangial, sugestivo de glomerulonefrite mesangioproliferativa (Figura 9).

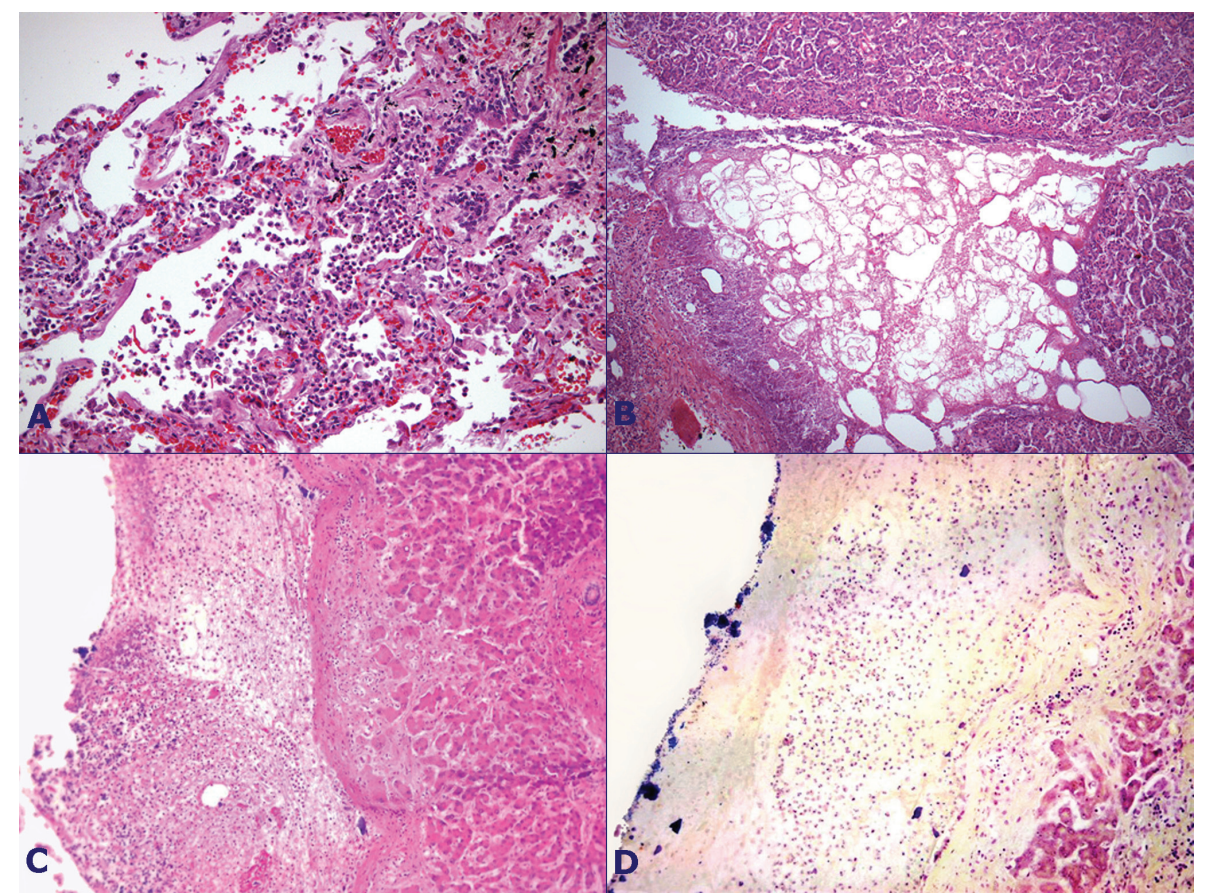

Figura 8 - Fotomicrografias mostrando: A e B - Parênquima pulmonar alveolado com infiltrado inflamatório agudo no espaço alveolar caracterizando broncopneumonia (HE - 200X). B - Parênquima pancreático com esteatonecrose e infiltrado inflamatório agudo associado (HE - 100X). C - Deposição de tampão fibrino-leucocitário em cápsula de Glisson no fígado, representando peritonite aguda (HE - 100X). D - Colônias de bactérias tipo cocos gram positivos na superfície do tampão fibrino-leucocitário (Brown-Hopps - 100X).

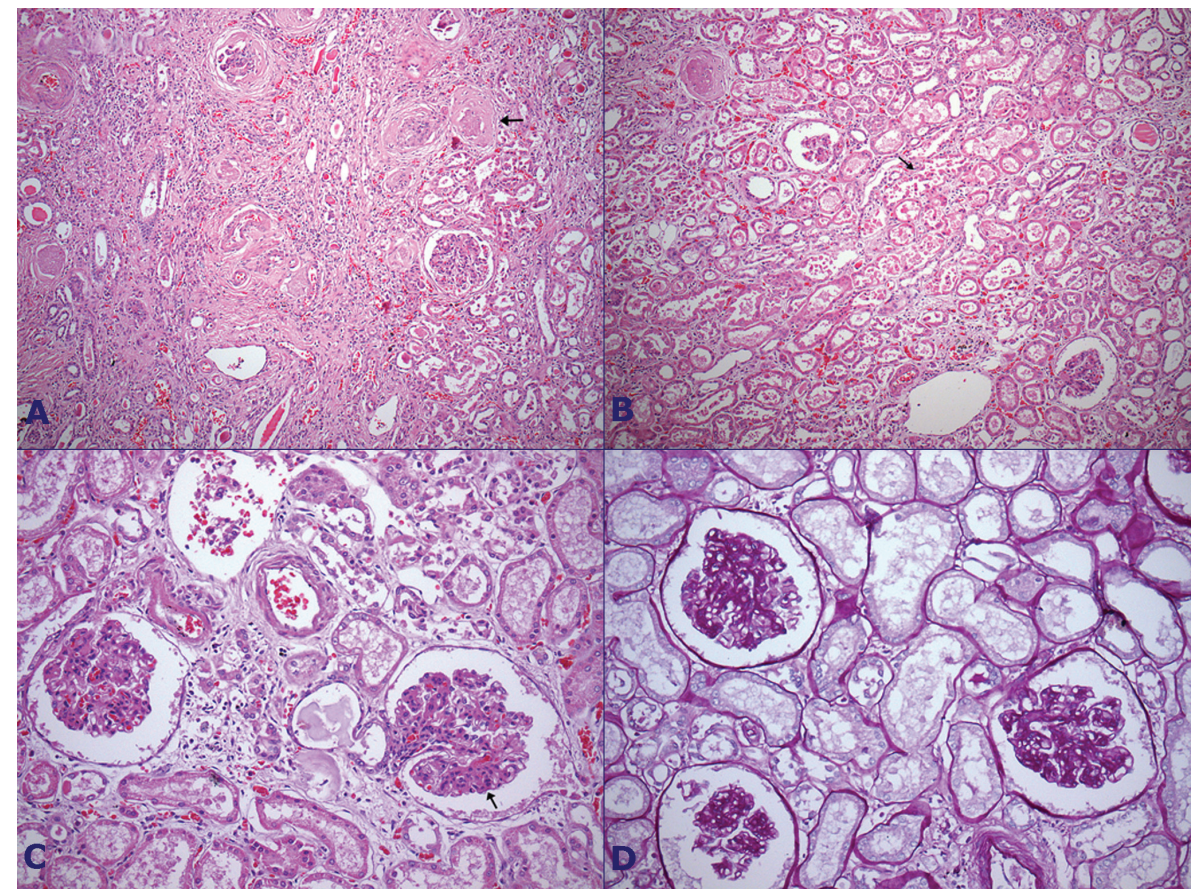

Figura 9 - Fotomicrografias mostrando: A - Pielonefrite crônica inespecífica discreta com glomérulos hialinizados (seta) representando nefroesclerose benigna (HE - 100X). B - Túbulos renais com descamação epitelial intra-luminal (seta) característico da necrose tubular aguda renal (HE - 100X). C - Glomérulos com espessamento da matriz mesangial com discreta hipercelularidade sugestivo de glomerulonefrite mesangioproliferativa (seta) (HE-200X). D - Espessamento da matriz mesangial em glomérulos (PAS - 200X). 


\section{DISCUSSÃO}

Em 1852, Raphael Lucio e Ignacio Alvarado $^{7}$ publicaram um artigo baseado na experiência observacional de 8 anos no Hospital de los Lazarinos (cidade do México). Neste trabalho, intitulado de Opúsculo de La Enfermedad de San Lázaro o Elefancíasis de los Griegos, descreveram três formas clínicas de apresentação da lepra com especial atenção à forma "manchada" ou lepra Lazarina. Esta forma caracterizava-se pela presença de manchas eritematosas, dolorosas, que evoluíam para necrose e pela ausência de lesões infiltrativas nodulares. A necrose tecidual, que se desenvolvia sobre estas lesões, formava úlcera que evoluía para cicatriz hipocrômica com bordas hiperpigmentadas. ${ }^{8,9} \mathrm{Em}$ 1941 Martinez Baez ${ }^{10}$ estudou as lesões necróticas de 5 pacientes e observou que a estrutura básica desta forma de lepra consistia em vasculite aguda com restos nucleares, espessamento e oclusão de vasos maiores produzindo necrose. Em 1948 Latapí e Chevez-Zamora adicionaram mais características à descrição original de Lucio e Alvarado, destacando a infiltração cutânea como generalizada e difusa sobre a qual as reações necróticas cutâneas secundárias se manifestavam, chamaram-na de lepra primitiva difusa e pura ou lepra difusa de Lúcio e Latapí. Estas manifestações decorriam de vasculite necrotizante que denominaram de "Fenômeno de Lúcio" ou "Eritema Necrotizante". ${ }^{6}$ A lepra difusa de Lúcio e Latapí é considerada a mais anérgica de todo o espectro imunológico hansênico, sendo caracterizada pela infiltração cutânea difusa, sem nódulos, "suculenta" ou atrófica (dependendo do estágio evolutivo), com disestesia, anidrose, alopecia, rinite destrutiva com deformidade em sela do nariz, telangiectasia e podendo ter a presença do fenômeno de Lúcio ou Eritema Necrotizante, uma forma especial de reação à lepra. ${ }^{8,11,12}$

No presente caso relatado, a paciente procurou o serviço médico devido ao aparecimento recente de múltiplas lesões cutâneas ulceradas de bordas irregulares, em diferentes estágios de evolução, algumas com aspecto necrótico e outras com deposição de material fibrino-purulento com infecção secundária. Embora não tivesse diagnóstico prévio, a paciente apresentava ao exame físico sinais indicativos do diagnóstico de lepra difusa de Lúcio e Latapí, como pele de aspecto infiltrado, mixedematoso e sem nódulos, mãos em garra, madarose e nariz em sela, sendo as lesões ulceradas extensas secundárias ao quadro reacional do fenômeno de Lúcio. O quadro clínico de entrada da paciente é correspondente ao descrito na literatura. O fenômeno de Lúcio se manifesta de três a quatro anos após o início da doença, geralmente em pacientes não tratados ou inadequadamente tratados e tende a desaparecer de seis a oito semanas após o início da terapia adequada. ${ }^{13}$ Clinicamente o fenômeno de Lúcio é caracterizado por agrupamentos de máculas irregulares bem delimitadas, de coloração vinhosa, com sensação de queimação, com centro purpúrico que se torna necrótico evoluindo para cicatriz atrófica. As lesões podem coexistir em diferentes fases evolutivas no mesmo paciente. Vesículas e bolhas podem eventualmente ser observadas. ${ }^{14}$ Estas lesões costumam iniciar nos membros inferiores e ascenderem para nádegas, membros superiores, mãos e mais raramente dorso e face. É descrito parestesia das mãos e pés, hipo ou anidrose, alopecia da sobrancelha e/ou cílios, pele rosada e lisa com aparência de pele sadia que depois se torna mixedematosa especialmente nas mãos e face. ${ }^{13} \mathrm{Em}$ uma série de 30 pacientes estudados por Rea e Jerskey somente 4 pacientes tinham o diagnóstico de hanseníase antes do desenvolvimento do fenômeno de Lúcio. ${ }^{14}$

O quadro laboratorial pode revelar leucocitose, neutrofilia, anemia, velocidade de hemossedimentação elevada, hipoalbuminemia, hipocalcemia, falso resultado positivo para anticorpos cardiolipínicos para sífilis e hipergamaglobulinemia. ${ }^{15,16}$ No fenômeno de Lúcio os sintomas sistêmicos quando presentes, em geral, estão relacionados à presença de complicações como infecções bacterianas secundárias e sepse ou patologias prévias, com altas taxas de mortalidade. ${ }^{4,17}$ Assim também a nossa paciente teve evolução fatal devido ao quadro séptico, com infecção bacteriana secundária nas lesões cutâneas, muitas das quais apresentando secreção purulenta. Além da broncopneumonia, a paciente desenvolveu, provavelmente devido a fenômenos circulatórios de má perfusão tecidual relacionado ao quadro séptico, pancreatite aguda com esteatonecrose, levando a peritonite aguda fibrinopurulenta e necrose tubular aguda renal, com repercussão clínica final de insuficiência renal aguda. A paciente ainda apresentava diabetes mellitus tipo Il como co-morbidade, cuja prevalência é aumentada em pacientes com hanseníase, principalmente nas formas multibacilares, com taxa de até $14,2 \%$ versus $2,0 \%$ no grupo controle. ${ }^{18}$

Histologicamente o fenômeno de Lúcio começa com a colonização das células endoteliais pelo Mycobacterium leprae e exibe 2 padrões. O primeiro envolve dano vascular devido à invasão direta do Mycobacterium leprae, levando a oclusão vascular por proliferação de células endoteliais, trombose, discreto infiltrado mononuclear e então necrose is- 
quêmica e ulceração cutânea. O segundo é representado por um estado reacional agudo com vasculite leucocitoclástica de pequenos vasos dérmicos, possivelmente desencadeado por imunocomplexos com antígenos da lepra, podendo também apresentar paniculite lobular e espessamento miointimal de pequeno e médio calibre..$^{8,19-21}$ Também observamos nos recortes histológicos da pele os 2 padrões morfológicos descritos no fenômeno de Lúcio. Nas bordas e fundo das lesões ulcero-necróticas havia pequenos vasos dérmicos com vasculite leucocitoclástica, além de discreto infiltrado inflamatório linfomonoclear e presença de bacilos álcool ácido resistentes colonizando células endoteliais, porém sem histiócitos xantomizados (células de Virchow). Documentamos ainda alguns vasos na derme reticular profunda com espessamento da parede por proliferação miointimal e outros com trombo de fibrina nos lúmens. Somente na pele adjacente, com aspecto infiltrado e mixedematoso, observamos denso infiltrado com histiócitos xantomizados com numerosos bacilos intra-citoplasmáticos (células de Virchow), característico da lepra difusa de Lúcio e Latapí, ressaltando, segundo a literatura, a importância de considerar o diagnóstico de lepra em quadros de vasculite necrotizante mesmo na ausência de células de Virchow no infiltrado inflamatório, com a pesquisa de BAAR através de colorações especiais. ${ }^{13}$

Considerando que a lepra é uma doença sistêmica, o Mycobacterium leprae infecta não somente a pele, como também pode acometer órgãos internos. O envolvimento visceral é mais comum nas formas multibacilares, nos polos borderline e virchowiano, sendo a disseminação hematogênica provavelmente um importante mecanismo de envolvimento dos órgãos internos. ${ }^{22} \mathrm{~A}$ presença de leproma miliar é descrita em vários órgãos do sistema reticulo endotelial, como medula óssea, fígado e baço, bem como glândula supra-renal e sistema nervoso periférico. ${ }^{21,22} \mathrm{~A}$ incidência do acometimento hepático nas formas multibacilares varia de $48 \%$ a aproximadamente $100 \%$, mas os pacientes são geralmente assintomáticos, sem alterações das enzimas hepáticas nos exames laboratoriais ${ }^{22,23}$, assim como observado na nossa paciente, que não apresentava hepatomegalia ou alterações laboratoriais relacionadas a função hepática. Observamos também o acometimento visceral com leproma miliar no baço e focalmente na medula óssea e supra-renal. Apesar de no rim não apresentar alterações de infecção direta pelo M. leprae, observamos discreta expansão da matriz mesangial nos glomérulos, sugestivo de glomerulonefrite mesangioproliferativa. A incidência de glomerulonefrites em pacientes com lepra va- ria de $6 \%$ a $50 \%$ na literatura, sendo a glomerulonefrite mesangioproliferativa a mais comum. ${ }^{22,24}$

O diagnóstico diferencial das lesões necróticas em pacientes portadores de hanseníase é feito entre o fenômeno de Lúcio e eritema nodoso lepromatoso, e depende muito da correlação clínica. Caracteristicamente o eritema nodoso lepromatoso se desenvolve sobre nódulos (lepromas) como parte de um estado reacional freqüentemente após início de terapêutica específica, enquanto o fenômeno de Lúcio ocorre em pacientes com doença não nodular e antes de iniciada a terapêutica. Estas duas entidades resultam de mecanismo imunológico similar, conhecida como vasculite imunomediada, caracterizada por inflamação leucocitoclástica e deposição de imunocomplexos (IgG e C3) na parede de vasos da derme e hipoderme ${ }^{12,25}$. Nas lesões cutâneas no fenômeno de Lúcio há também agressão direta das células endoteliais por bacilos álcool acido resistentes (BAAR) ${ }^{26}$ Uma vez instalada a necrose, uma resposta inflamatória secundária se sobrepõe atraindo para o local as células inflamatórias, imunocomplexos e outros mediadores inflamatórios, dificultando o diagnóstico diferencial. Ambas as condições predispõem a infecção bacteriana e sepse, estando freqüentemente associadas à alta taxa de mortalidade ${ }^{18,27}$, mas é importante o diagnóstico diferencial considerando as diferenças na conduta terapêutica. Enquanto o tratamento do fenômeno de Lúcio visa diminuir a carga bacilar com terapia por multidrogas, o tratamento do eritema nodoso lepromatoso visa diminuir a reação inflamatória com talidomida ou corticóide. ${ }^{20}$

O diagnóstico de fenômeno de Lúcio é desafiador considerando que em geral o paciente chega ao serviço médico sem diagnóstico prévio de hanseníase, sendo necessária correlação com o quadro clínico do doente, bem como biópsias múltiplas de lesões representativas, para confirmação diagnóstica. Lembrando que o Brasil é um país com alta incidência de hanseníase, é imperativa a pesquisa de BAAR nas lesões cutâneas suspeitas. Esse relato de caso ilustra a dificuldade do diagnóstico de hanseníase nos estados reacionais.

\section{AGRADECIMENTOS}

Os autores agradecem a Rosa Maria da Conceição Zanardi pelo auxílio na documentação das imagens apresentadas. 


\section{REFERÊNCIAS}

1. Secretaria de Estado da Saúde (SP). Centro de Vigilância Epidemiológica Prof. Alexandre Vranjac. Hanseníase [Internet]. São Paulo: CVE; 2009 [cited 2011 May 6]. Available from: ftp://ftp.cve.saude.sp.gov.br/doc tec/hans/ hans09_dados.pdf Portuguese.

2. Situation of leprosy. Wkly Epidemiol Rec. 2007;82:165-72.

3. Walker SL, Lockwood DN. Leprosy. Clin Dermatol. 2007;25:165-72.

4. Bernard G, Sakai-Valente NY, Trindade MAB. Am J Dermatopathol. 2009;31:288-92.

5. Kahawita IP, Lockwood DN. Towards understanding the pathology or erythema nodosumleprosum. Trans R Soc Trop Med Hyg. 2008;102:329-37.

6. Latapi F, Zamora AC. The" spotted" leprosy of Lucio (La "manchada "de Lucio); anintroductiontoits clinical and histologicalstudy. Lepr Rev. 1948;16:421-37.

7. Lucio R, Alvarado I. Opúsculo sobre el mal de San Lázaro e elefancíasis de los Griegos. In: González-Urueña J, editor.La lepra emMexico. Buenos Aires: El Ateneo;1941. p 199-231. Spanish.

8. Vargas-Ocampo F. Diffuse leprosy of Lucio and Latapí a histologic study. Lepr Rev. 2007;78:248-60.

9. Kumari R, Thappa DM, Basu D. A fatal case of Lucio phenomenon from India. Dermatol Online J. 2008;14:10.

10. Martínez-Báez M. Nota preliminar sobre la histopatología de las manifestaciones cutaneas de la "forma de Lúcio" de la lepra. Rev Inst Salub Enf Trop. 1941;2:245-56. Spanish.

11. Donner RS, Shively JA. The "Lucio Phenomenon" in diffuse leprosy. Ann Intern Med. 1967;67:831-6.

12. Saul A, Novales J. Lucio-Latapíleprosyandthe Lucio phenomenon. Acta Leprol. 183;1:115-32.

13. Fagagnolo L, Souza EM, Cintra ML, Velho PENF. Vasculonecrotic Reactions in Leprosy. Bras J Infect Dis. 2007; 11:378-82.

14. Rea TH, Jerskey RS. Clinical and histological variations among thirty patients with Lucio's phenomenon and pure primitive diffuse lepromatosis (Latapi'slepromatosis). Int $J$
Lepr Other Mycobact Dis. 2005;73:169-88.

15. Sehgal VN. Lucio's phenomenon/erythema necroticans. Int J Dermatol. 2005;44:602-5.

16. Choon SE, Tey KE. Lucio's phenomenon: a report of three cases in Johor, Malaysia. Intern J Dermatol. 2009:48:984-8

17. Costa IM, Kawano LB, Pereira CP, et al. Lucio's phenomenon: a case report and review of literature. Int J Dermatol. 2005;44:566-71.

18. Ponte CMM, Gurgel MHC, Ponte GA, et al. Distúrbios metabólicos em doenças infecciosas emergentes e negligenciadas. Arq Bras Endocrinol Metab. 2010;54/9:785792. Portuguese.

19. Moschella SL. The lepra reaction with necrotizing skin lesions: a report of six cases. Arch Derm. 1967; 95:567-75.

20. Rea TH, Levan NE. Lucio's phenomenon and diffuse nonnodularlepromatous leprosy. Arch Dermatol. 1978;114:1023-8

21. Bernard JC, Vazquez CAJ. Visceral lesions in lepromatous leprosy; study of sixty necropsies. Int J Lepr. 1973;41:94-101.

22. Klioze AM, Ramos-Caro FA. Visceral leprosy. Int J Dermatol. 2000;39:641-658.

23. Verghese $A$, Job CK. Correlation of liver function with the pathology of the liver in leprosy. Int J Lepr. 1965;33:342-8.

24. Grover S, Bobhate SK, Chaubey BS. Renal abnormality in leprosy. Lepr India 1983;55:286-91.

25. Quismorio FPJr, Rea T, Chandor S, Norman L, Friou GF. Lucio's Phenomenon: animmune complex deposition syndrome in lepromatous leprosy. Clin Immunol Immunopathol. 1978;9:184-93.

26. Rea TH, Riddley DS. Lucio's phenomenon: a comparative histological study. Int J Lepr Other Mycobact Dis. 1979;47:161-6.

27. Ang P,Thay YK, Ng SK, et al. Fatal Lucio's phenomenon in 2 patients with previously undiagnosed leprosy. J Am AcadDermatol. 2003; 48:958-61.

\section{Conflito de interesse: Não}

Submetido em: 05 de Maio de 2011

Aceito em: 24 de Maio de 2011

Correspondência: Divisão de Clínica Médica

Av. Prof. Lineu Prestes, 2565 - Cidade Universitária - São Paulo - SP - Brasil

CEP: 05508-000 - Tel.: +55.11. 3091.9200

E-mail: ffcampos@usp.br 